\title{
Relationship of the Personal, Socio-psychological and Communication Variables with Symbolic Adoption of the Tomato Growers through Different Information and Communication Technology (ICT) Gadgets
}

\author{
Shivani Dechamma ${ }^{1}$, V. Govinda Gowda ${ }^{2}$ and M. B. Shanabhoga ${ }^{1}$ * \\ ${ }^{1}$ Department of Agricultural Extension, University of Agricultural Extension, GKVK, \\ Bengaluru-65, India \\ ${ }^{2}$ Krishi Vigyana Kendra, Tiptur, Tumkur district, India \\ *Corresponding author
}

\section{Keywords}

Symbolic adoption,

Information and

Communication

Technology (ICT),

television, e-krishi agri portal, DVD

\section{Article Info}

Accepted:

08 January 2020

Available Online:

10 February 2020

\section{A B S T R A C T}

Information may come to farmers from various sources. It may be from personal, impersonal, institutional, localite and cosmopolite or mass media sources. The appropriateness of these sources varies from enterprise to enterprise, situation to situation and from time to time. Further, the credibility of information sources also varies with respect to the competency and trustworthiness of the source. Hence, it becomes quite important to channelize the right information at the right time and through the right channel.The "Before and After" research design was employed for conducting the study. The present study was conducted in Bangalore rural district of Karnataka state. Hoskote taluk was purposively selected for the study where tomato is extensively cultivated. The total sample constitute to 90 from three villages. The study shows that a positive and significant relationship between symbolic adoption of the tomato growers with their family size, cosmopoliteness, economic motivation and deferred gratification before the treatment. Whereas, education, family size, farming experience, extension contact, economic motivation, innovative proneness and risk orientation had a significant relationship after the television treatment. The data reveals that a positive and significant relationship between symbolic adoption of the tomato growers with farming experience, scientific orientation, innovative proneness and risk orientation before the treatment. Whereas, farming experience, scientific orientation, achievement motivation, innovative proneness and management orientation had a significant relationship after the e-krishi Agri -portal treatment. The results reveals that a positive and significant relationship between symbolic adoption of tomato growers with age, family size, scientific orientation, innovative proneness and management orientation before the treatment. Whereas, family size, scientific orientation, achievement motivation, deferred gratification, and risk orientation had significant relationship after the DVD treatment. 


\section{Introduction}

Agriculture continues to be the occupation and way of life for more than half of Indian population even today, making single largest contribution to the GDP of our nation. Sustainable prosperity of the farmers and the agricultural labourers holds the key for improving the overall human resource development scenario in the country. Indian agriculture had been on traditional lines till the first waves of green revolution in the late 1960s. The green revolution gave a sudden boost to the production and productivity by making India self-sufficient. Though India has achieved self-sufficiency in food grain production, we cannot complacently with the increasing population. There is a need to increase production and productivity of agriculture. Hence, the Indian farmers need to be updated with the latest knowledge about new techniques of farming, new cultivars, farm machinery, market and trade situation, etc.

The extension personnel of the department of agriculture disseminated the technologies and messages to the farmers through various extension methods. But these approaches have not been able to reach the majority of the farmers spread across the country as the ratio between farmer and extension worker is 1000:1. This gap remains a challenge for extension system even today. To reach 120 million farmers spread over more than 500 districts is an uphill task. The diversity of agro-ecological situations adds to this challenge further. Farmers' needs are much more diversified and the knowledge required to address them is beyond the capacity of the grass root level extension functionaries. In this context, Information and Communication Technologies (ICTs) play an important role in reaching the unreached, supplement and reinforce the extension efforts.
Communication is recognized as an important input for development to disseminate and create dialogue among different stakeholders about the technologies and issues of agriculture, environment and sustainable development. ICTs are technologies offering new ways for communicating and exchanging information and knowledge. While ICT is gaining prominence as an engine for economic growth it also promises to have far reaching potential for the delivery of social services, enhancing the effectiveness of government administration. India has surfaced as a country with a sound foothold in the field of ICT. Large scale investments are being made to enhance the potential of ICT sector in India. Such investments would prove more cost effective if the resources of the IT sector are blended with that of the agricultural sector in India thereby making the two ends of the thread meet. The ICT gadgets like radio, television, vedio, films, computer, internet, mobiles etc., which have the potential of providing a vast amount of relevant information to rural population in timely, comprehensive and cost effective manner. The new ICTs are the driving forces of globalization. They are bringing people and decision makers together with unprecedented new tools for development. In the present era of information revolution, the ability to acquire and use information is regarded as a national asset. Information is considered as a resource much like land, labour and capital. Access to information and improved communication is, therefore, considered as a crucial requirement for the success of any development efforts. Agriculture is no exception to this phenomenon.

\section{Materials and Methods}

\section{Research design}

The "Before and After" research design was employed for conducting the study. 


\section{Locale of the study}

The present study was conducted in Bangalore rural district of Karnataka state. Hoskote taluk was purposively selected for the study where tomato is extensively cultivated. Three villages namely Doddadenahalli, Alugondanahalli and Chikkathagalli were selected for the study.

\section{Selection of respondents}

From each village 30 tomato growers were selected constituting a total sample size of 90 [ $\left(30\right.$ farmers for television treatment $\left(\mathrm{T}_{1}\right)+30$ farmers for e-krishi Agri-portal $\left(\mathrm{T}_{2}\right)+30$ farmers for DVD treatment $\left.\left(\mathrm{T}_{3}\right)\right]$. Before and after experimental research design was employed to know the relative effectiveness of television (T1), e- krishi Agri-portal (T2) and DVD (T3) on tomato crop production practices among farmers.

\section{Data processing and analysis}

Data was collected by using a detailed interview schedule by employing personal interview method. The data was collected two times for each treatment, once before the treatment and again after the treatment. The statistical tests like percentage, mean, standard deviation and chi-square test were employed for analysis and interpretation of data.

\section{Results and Discussion}

Relationship of the personal, sociopsychological and communication variables with symbolic adoption of the tomato growers through television treatment

The review of table 1 reveals that family size, cosmopoliteness, economic motivation, and deferred gratification were positively and significantly related to the symbolic adoption of the tomato growers with respect to television treatment at five per cent level of significance before the treatment. Other variables namely age, education, farming experience, land holding, mass media exposure, extension contact, extension participation, scientific orientation, achievement motivation, innovative proneness, risk orientation and management orientation were not significantly related to the symbolic adoption of the tomato growers.

Further the review of table 1reveals that education, farming experience, extension contact, economic motivation, innovative proneness and risk orientation were significantly related to the symbolic adoption of tomato growers with respect to television treatment at 5 per cent level of significance after the treatment and family size was significantly related at 1 per cent level of significance. Other characteristics namely age, land holding, cosmopoliteness, mass media exposure, extension participation, scientific orientation, achievement motivation, deferred gratification and management orientation were not significantly related to the symbolic adoption of the tomato growers.

The possible reason for the significant relationship between symbolic adoption level and the independent variables in the television treatment is that the family size might have influenced in getting more profit which might have lead symbolic adoption favourable. The significance of cosmopoliteness is might be due to the fact that the farmers who make frequent visits to outside places will be exposed to new ideas, technologies and awareness.

Regarding economic motivation, it is quite imperative to expect those growers having a desire to excel economically would operate their farm successfully by adopting the 
recommended practices. The probable reason for significance of deferred gratification is due to their increased yield and also may be due to increased saving pattern of farmers keeping the future requirements in their mind.

Education level of the individual directly relates to the symbolic adoption of the farmer. It is a normal tendency that the individual with higher education will be consulted more by the fellow farmers regarding the farm activities.

Regarding significant relationship of farming experience, tomato is a traditional crop of the project area, growers knowledge and experience with respect to the crop was very high, thus it is simple and easy to adopt. The farmers having more extension contact with the agencies will have a better symbolic adoption due to broad spectrum of new information.

In case of risk orientation, farmers are ready to take more risk because of their instinct to come up in their life and settle comfortably, the possible reason for significant relationship innovative proneness of the farmer which result in increasing quest to novel ideas and fact which can aid them in increasing productivity. These findings are in agreement with the findings of Anandaraja (2002) and Senthil Kumar (2003).

Relationship of the personal, sociopsychological and communication variables with symbolic adoption of the tomato growers through e-krishi Agri-portal treatment

The data in table 2 reveals that farming experience, scientific orientation innovative proneness and risk orientation were positively and significantly related to the symbolic adoption of the tomato growers with respect to e-krishi Agri - portal treatment at five per cent level of significance before the treatment.
Other variables namely age, family size, education, land holding, cosmopoliteness, mass media exposure, extension contact, extension participation, economic motivation, achievement motivation, deferred gratification, and management orientation were not significantly related to the symbolic adoption of the tomato growers.

Further the review of table 2 also reveals that farming experience, scientific orientation, achievement motivation, management orientation and innovative proneness were significantly related to the symbolic adoption of tomato growers with respect to e-krishi Agri - portal treatment at 5 per cent level of significance after the treatment. Other characteristics namely age, education, family size, land holding, cosmopoliteness, mass media exposure, extension contact, extension participation, economic motivation, deferred gratification and risk orientation were not significantly related to the symbolic adoption of the tomato growers.

The possible reason for the significant relationship between symbolic adoption level and the independent variables during the ekrishi Agri - portal treatment is that Farming experience further helps farmers to select new crops, technologies and enterprises to fetch more profits and sustenance and hence it is significantly related. It is imperative that scientifically oriented farmers will have a positive attribute towards gaining scientific aspects of cultivation. Farmers normally possess higher innovative proneness since they always look forward for new things and new ways of doing things, so it is significantly related.

Risk orientation is the quality of any individual to excel in their activity and hence it is positively and significantly associated with the increase in symbolic adoption level of farmers. 
The reason for significance of achievement motivation may be interest of the individual to decide and complete the tasks in certain directions, which in turn helps in achieving the desired crop yield and income.
Management orientation will help the farmers in taking decisions regarding the progressiveness of the farm and reorient them. These results coincide with the results of Vanetha (2008).

Table.1 Relationship of the personal, socio-economic, psychological and communication variables with symbolic adoption of crop production practices among tomato growers under

Television treatment

\begin{tabular}{|r|l|c|c|}
\hline SL NO. & \multicolumn{1}{|c|}{ Independent variables } & \multicolumn{2}{|c|}{ Correlation coeffecient (r) } \\
\hline $\mathbf{1}$ & Age & Before & After \\
\hline $\mathbf{2}$ & Education & $0.022^{\mathrm{NS}}$ & $0.145^{\mathrm{NS}}$ \\
\hline $\mathbf{3}$ & Family size & $0.201^{\mathrm{NS}}$ & $0.439^{*}$ \\
\hline $\mathbf{4}$ & Farming experience & $0.393^{*}$ & $0.481^{*}$ \\
\hline $\mathbf{5}$ & Land holding & $0.118^{\mathrm{NS}}$ & $0.413^{*}$ \\
\hline $\mathbf{6}$ & Cosmopoliteness & $0.062^{\mathrm{NS}}$ & $0.039^{\mathrm{NS}}$ \\
\hline $\mathbf{7}$ & Mass media exposure & $0.356^{*}$ & $0.202^{\mathrm{NS}}$ \\
\hline $\mathbf{8}$ & Extension contact & $0.078^{\mathrm{NS}}$ & $0.089^{\mathrm{NS}}$ \\
\hline $\mathbf{9}$ & Extension participation & $0.030^{\mathrm{NS}}$ & $0.383^{*}$ \\
\hline $\mathbf{1 0}$ & Economic motivation & $0.143^{\mathrm{NS}}$ & $0.043^{\mathrm{NS}}$ \\
\hline $\mathbf{1 1}$ & scientific orientation & $0.378^{*}$ & $0.444^{*}$ \\
\hline $\mathbf{1 2}$ & Achievement motivation & $0.100^{\mathrm{NS}}$ & $0.099^{\mathrm{NS}}$ \\
\hline $\mathbf{1 3}$ & Deferred gratification & $0.198^{\mathrm{NS}}$ & $0.091^{\mathrm{NS}}$ \\
\hline $\mathbf{1 4}$ & Innovative proneness & $0.035^{\mathrm{NS}}$ & $0.120^{\mathrm{NS}}$ \\
\hline $\mathbf{1 5}$ & Risk orientation & $0.407^{*}$ & $0.527^{*}$ \\
\hline $\mathbf{1 6}$ & Management orientation & $0.299^{\mathrm{NS}}$ & $0.115^{\mathrm{NS}}$ \\
\hline & & & \\
\hline & & & \\
\hline & & & \\
\hline
\end{tabular}


Table.2 Relationship of the personal, socio-economic, psychological and communication variables with symbolic adoption of crop production practices among tomato growers under e-

krishi Agri-portal treatment

\begin{tabular}{|c|c|c|c|}
\hline \multirow[t]{2}{*}{ SL NO. } & \multirow[t]{2}{*}{ Independent variables } & \multicolumn{2}{|c|}{ Correlation coeffecient (r) } \\
\hline & & Before & After \\
\hline 1 & Age & $0.039^{\mathrm{NS}}$ & $0.025^{\mathrm{NS}}$ \\
\hline 2 & Education & $0.133^{\mathrm{NS}}$ & $0.175^{\mathrm{NS}}$ \\
\hline 3 & Family size & $0.013^{\mathrm{NS}}$ & $0.061^{\mathrm{NS}}$ \\
\hline 4 & Farming experience & $0.372 *$ & $0.453^{*}$ \\
\hline 5 & Land holding & $0.003^{\mathrm{NS}}$ & $0.066^{\mathrm{NS}}$ \\
\hline 6 & Cosmopoliteness & $0.046^{\mathrm{NS}}$ & $0.023^{\mathrm{NS}}$ \\
\hline 7 & Mass media exposure & $0.021^{\mathrm{NS}}$ & $0.038^{\mathrm{NS}}$ \\
\hline 8 & Extension contact & $0.127^{\mathrm{NS}}$ & $0.106^{\mathrm{NS}}$ \\
\hline 9 & Extension participation & $0.014^{\mathrm{NS}}$ & $0.056^{\mathrm{NS}}$ \\
\hline 10 & Economic motivation & $0.144^{\mathrm{NS}}$ & $0.104^{\mathrm{NS}}$ \\
\hline 11 & scientific orientation & $0.458 *$ & $0.365^{*}$ \\
\hline 12 & Achievement motivation & $0.106^{\mathrm{NS}}$ & $0.391 *$ \\
\hline 13 & Deferred gratification & $0.141^{\mathrm{NS}}$ & $0.037^{\mathrm{NS}}$ \\
\hline 14 & Innovative proneness & $0.413^{*}$ & $0.358 *$ \\
\hline 15 & Risk orientation & $0.441 *$ & $0.187^{\mathrm{NS}}$ \\
\hline 16 & Management orientation & $0.071^{\mathrm{NS}}$ & $0.452 *$ \\
\hline
\end{tabular}

*Significant at $5 \%$ level, NS: Non- significant

Table.3 Relationship of the personal, socio-economic, psychological and communication variables with symbolic adoption of crop production practices among tomato growers under

DVD treatment

$(\mathbf{n}=\mathbf{3 0})$

\begin{tabular}{|c|c|c|c|}
\hline \multirow[t]{2}{*}{ SL NO. } & \multirow[t]{2}{*}{ Independent variables } & \multicolumn{2}{|c|}{ Correlation coeffecient (r) } \\
\hline & & Before & After \\
\hline 1 & Age & $0.391 *$ & $0.003^{\mathrm{NS}}$ \\
\hline 2 & Education & $0.163^{\mathrm{NS}}$ & $0.038^{\mathrm{NS}}$ \\
\hline 3 & Family size & $0.424^{*}$ & $0.444^{*}$ \\
\hline 4 & Farming experience & $0.007^{\mathrm{NS}}$ & $0.130^{\mathrm{NS}}$ \\
\hline 5 & Land holding & $0.090^{\mathrm{NS}}$ & $0.087^{\mathrm{NS}}$ \\
\hline 6 & Cosmopoliteness & $0.048^{\mathrm{NS}}$ & $0.146^{\mathrm{NS}}$ \\
\hline 7 & Mass media exposure & $0.047^{\mathrm{NS}}$ & $0.066^{\mathrm{NS}}$ \\
\hline 8 & Extension contact & $0.041^{\mathrm{NS}}$ & $0.134^{\mathrm{NS}}$ \\
\hline 9 & Extension participation & $0.048^{\mathrm{NS}}$ & $0.167^{\mathrm{NS}}$ \\
\hline 10 & Economic motivation & $0.078^{\mathrm{NS}}$ & $0.077^{\mathrm{NS}}$ \\
\hline 11 & scientific orientation & $0.378 *$ & $0.376^{*}$ \\
\hline 12 & Achievement motivation & $0.156^{\mathrm{NS}}$ & $0.372 *$ \\
\hline 13 & Deferred gratification & $0.050^{\mathrm{NS}}$ & $0.406^{*}$ \\
\hline 14 & Innovative proneness & $0.438 *$ & $0.082^{\mathrm{NS}}$ \\
\hline 15 & Risk orientation & $0.009^{\mathrm{NS}}$ & $0.377 *$ \\
\hline 16 & Management orientation & $0.446^{*}$ & $0.074^{\mathrm{NS}}$ \\
\hline
\end{tabular}

*Significant at $5 \%$ level, NS: Non- significant 
Relationship of the personal, sociopsychological and communication variables with symbolic adoption of the tomato growers through DVD treatment

The data in table 3 reveals that age, family size, scientific orientation, management orientation and innovative proneness were positively and significantly related to the symbolic adoption of the tomato growers with respect to DVD treatment at five per cent level of significance before the treatment. Other variables namely farming experience, education, land holding, cosmopoliteness, mass media exposure, extension contact, extension participation, economic motivation, achievement motivation, deferred gratification, and risk orientation were not significantly related to the symbolic adoption of the tomato growers.

Further the review of table 3 also reveals that family size, achievement motivation, scientific orientation, deferred gratification and risk orientation were significantly related to the symbolic adoption of tomato growers with respect to DVD treatment at five per cent level of significance after the treatment. Other characteristics namely Age, education, farming experience, land holding, cosmopoliteness, mass media exposure, extension contact, extension participation, economic motivation, innovative proneness and management orientation were not significantly related to the symbolic adoption of the tomato growers.

The possible reason for the significant relationship between symbolic adoption level and the independent variables during the DVD treatment is that as age increases the involvement of the farmers and also the enthusiasm in adopting farming technologies will increases and hence the result.

The family size might have influenced in getting more profit by making symbolic adoption favourable. It is imperative that scientifically oriented farmers will have a positive attribute towards gaining scientific aspects of cultivation and hence it is significantly related to symbolic adoption.

In addition, Risk orientation is the quality of any individual to excel in their activity, in the same manner achievement motivation and innovative proneness influences the urge of the individual to excel in their life and hence these variables are significantly associated.

Management orientation is significantly associated with symbolic adoption of tomato technologies as it enhances the confidence and skills of the individual to do varied work. The reason for deferred gratifications significant relationship with symbolic adoption is that tomato growers increased economic benefits and investment pattern might have developed positive attitude towards the tomato cultivation. The results were in line with the results of Anandaraja (2002).

In conclusion, twenty first century is characterized as information age. Information and communication technologies (ICT's) have become indispensable in our daily life to reinforce ourselves in the information society. ICTs can be broadly interpreted as technologies that facilitate communication, processing and transmission of information by electronic means. ICT in the present study deals with computer and internet. ICT provides an avenue to reach more farmers provided they are e-literate. Hence, ICT methods should be evolved to facilitate the better participation of stakeholders. Today's buzz word is "e"/electronic. So it is inevitable to practice e-Agriculture. Some of the ICT gadgets like television, computers, mobiles, internet etc., are effectively used by technologists to disseminate agricultural related information to the large mass of farmers. Many efforts are going on in 
designing agri. portals, decision support systems, expert systems and multimedia modules in agriculture. Universities, research institutes and development departments are utilizing these support systems to educate the farmers on various agriculture related aspects.

\section{Acknowledgement}

Authors are thankful to Department of Horticulture, Hoskote taluk, Bengaluru rural district for the support for interaction with the farmers, Department of Agricultural Extension, UAS, GKVK, Bengaluru for the support towards the completion of the research work and I would finally thank the farmers of the Hoskote taluk for the kind cooperation during the interaction.

\section{References}

Anandaraja, N., 2002, Developing Farmer Friendly Interactive Multimedia Compact Disc and Testing its Effectiveness in Transfer of Farm Technology. Ph.D. Thesis (Unpub.), TNAU, Coimbatore.

Senthilkumar, M., 2003, Field Testing Cyber Extension Techniques for Transfer of Farm Technology-A Feasibility Study. Ph. D. Thesis (Unpub.), TNAU, Coimbatore.

Vanetha, K. P., 2008, Teaching science and technology to tribal farm women through advanced communication gadgets. Ph.D. Thesis (Unpub.), TNAU, Coimbatore.

\section{How to cite this article:}

Shivani Dechamma, V. Govinda Gowda and Shanabhoga, M. B. 2020. Relationship of the Personal, Socio-psychological and Communication Variables with Symbolic Adoption of the Tomato Growers through Different Information and Communication Technology (ICT) Gadgets. Int.J.Curr.Microbiol.App.Sci. 9(02): 790-797. doi: https://doi.org/10.20546/ijcmas.2020.902.096 